\title{
DIAGNÓSTICO E PROPOSTA DE INTERVENÇÃO DE PRÁTICAS DE GESTÃO DO CONHECIMENTO: ESTUDO DE CASO NA ATIVA INCUBADORA DE EMPRESAS DO INSTITUTO FEDERAL DE EDUCAÇÃO, CIÊNCIA E TECNOLOGIA DE MATO GROSSO
}

\section{ARTIGO ORIGINAL}

SILVA, Carlos Marcelo Faustino da ${ }^{1}$

MORAIS, Léa Paula Vanessa Xavier Corrêa de ${ }^{2}$

SILVA, Carlos Marcelo Faustino da. MORAIS, Léa Paula Vanessa Xavier Corrêa de. Diagnóstico e proposta de intervenção de práticas de Gestão do Conhecimento: Estudo de caso na ativa incubadora de empresas do Instituto Federal de Educação, Ciência e Tecnologia de Mato Grosso. Revista Científica Multidisciplinar Núcleo do Conhecimento. Ano 05, Ed. 10, Vol. 05, pp. 16-50. Outubro de 2020. ISSN: 2448-0959, Link de acesso: https://www.nucleodoconhecimento.com.br/administracao/diagnostico-eproposta

\section{RESUMO}

Com a premissa de que o ambiente de empreendedorismo e inovação das incubadoras tem seus resultados otimizados quando se há uma gestão eficiente da criação, transferência, fluxo e aplicação do conhecimento, esta pesquisa teve como objetivo efetuar um estudo de caso da Ativa Incubadora de Empresas do IFMT para diagnosticar como se encontrava em relação as práticas de Gestão do Conhecimento e elaborar propostas de intervenção de acordo com o resultado. Foi aplicado um

1 Graduação em Ciências Contábeis pela Universidade Federal de Mato Grosso campus Rondonópolis, (2017).

2 Graduação em Agronomia pela Universidade Federal de Mato Grosso (2011) Mestrado em Agricultura Tropical pela Universidade Federal de Mato Grosso (2015). 
questionário na Gerência Executiva na incubadora, assim como em seus núcleos que se encontravam constituídos por todo o estado de Mato Grosso em 2019. Percebeuse que embora a maioria dos gestores dos núcleos não tivesse familiaridade com esse tipo de gestão, há uma percepção abrangente das práticas, entretanto, de forma pouco intensificada e muito defasada em alguns casos, como as práticas de banco de competências individuais, banco de competências organizacionais e sistema de gestão por competências. Como proposta de intervenção, sugeriu-se utilizar as práticas que já funcionam relativas à transferência do conhecimento para a socialização entre os núcleos que já possuem uma implantação efetiva e que geram resultados e aqueles que ainda se encontram defasados.

Palavras-chave: Incubadora, empreendedorismo, inovação, gestão do conhecimento.

\section{INTRODUÇÃO}

Com a constante evolução dos contextos em que se inserem a humanidade e o fluxo cada vez maior de informações, pode-se afirmar que transformações na sociedade são e serão sempre constantes. Atualmente muito se fala sobre a Sociedade do Conhecimento, termo que chegando ao final da década de 1990 acabou sobrepondose a Sociedade da Informação, uma vez que agora o foco é ampliado da informação para o processo dessa informação pelo ser humano (STRAUHS et. al., 2012).

Nesse contexto de rápida evolução que afeta diversas esferas, o conhecimento tornase fator primordial visto que com de grandes e contínuas transformações sociais, econômicas, políticas e culturais e a busca por formas de acompanhar as tendências dessas transformações, o conhecimento passou a ser o maior gerador de riquezas e o mais importante fator de produção (MAGNANI e HEBERLÊ, 2010).

Ressalta-se que o conceito de conhecimento está atrelado ao resultado da interpretação da informação e de sua utilização para alguma finalidade, ou seja, o uso da informação de modo a responder a um questionamento que busque resoluções ou até mesmo auxilie na tomada de decisões, assim criar-se conhecimento vai além da 
geração de dados e informações, atingindo formas de representações que fornecem significado e contexto para ações objetivas (PIMENTA e NETO, 2008).

Levando em conta a relevância do conhecimento, Strauhs et. al. (2012) colocam como fundamentais o papel da educação e as relações sociais por conta de os ambientes de criação do conhecimento necessitarem de muito mais do que tecnologia, tendo a indispensabilidade da participação de pessoas capazes de estar em permanente compartilhamento de ideias.

Nesse aspecto, fica clara a importância de se gerir o conhecimento, conforme apresentam Magnani e Heberê (2010) quando afirmam que esse tipo de gestão é o reconhecimento de que a informação e o conhecimento são ativos corporativos com grande potencial de otimizar resultados e que precisam ser devidamente compreendidos e gerenciados, assim, por meio de ferramentas específicas para sua natureza.

Os autores ainda trazem que tanto as organizações privadas quanto as públicas de qualquer setor se encontram inseridas num contexto globalizado de intensa competitividade, portanto necessitam trabalhar habilidades administrativas e aprimorar suas respectivas ferramentas de gestão (MAGNANI e HERBERÊ, 2010).

Logo, mesmo que a Gestão do Conhecimento (GC) seja um conceito mais amplamente difundido no ambiente de empresas privadas, é necessário atentar-se para sua prática na área pública, uma vez que na medida em que as organizações públicas são transformadas em instituições com foco no conhecimento, o conhecimento pode se tornar um de seus principais aliados (BATISTA, 2012).

Magnani e Herberê (2010) reforçam a ideia de que a GC deve também abranger a área pública quando iteram que existem significativos benefícios para o setor governamental quando adotam estratégias da gestão do conhecimento, principalmente para aquelas organizações em que é o fator humano que detém conhecimento de importância crítica e estratégica para suas ações futuras, que é o 
caso de organizações que trabalham intensamente com Pesquisa, Desenvolvimento e Inovação - PD\&I, onde a estrutura do conhecimento são essenciais.

Ou seja, em um aspecto geral a GC é tida como um importante método para mobilizar o conhecimento a fim de cumprir objetivos estratégicos de uma organização e melhorar seu desempenho (BATISTA, 2012).

Assim, levando em conta que vivemos este momento guiado pela relevância do conhecimento onde por consequência a inovação é parte fundamental para o desenvolvimento econômico e social de nossa sociedade (FURLANI, 2018), surge a perspectiva de estudo da GC no âmbito das incubadoras de empresas, visto que esses ambientes não devem ter seu papel resumido a simples criação de empresas, pois dentre seus vários propósitos encontra-se também o monitoramento para estimular o processo de inovação promovendo oportunidades para o desenvolvimento tecnológico, e concedendo, além de espaço físico, o apoio administrativo, aconselhamento e consultoria de diversas áreas (BAÊTA, 1999 apud BEUREN e RAUPP, 2003).

Dessa forma, por atuarem em ambientes voltados para a inovação, onde se necessita de posturas mais ativas com relação ao conhecimento organizacional utilizado, existe a premissa de que os indivíduos já se realizem nesses espaços algumas práticas e ações características para uma GC que ocorra de forma abrangente e efetiva (MÜLLER et. al., 2015).

Assim, com essa importante função de gerir negócios atribuídos às incubadoras, despertou-se o problema deste estudo de mensurar o quanto a Ativa Incubadora de Empresas do Instituto Federal de Educação, Ciência e Tecnologia do Mato Grosso tem acompanhado a evolução da Sociedade do Conhecimento e desenvolvido em suas atividades práticas de GC a fim de melhorar seu ambiente interno e torná-lo mais propício não apenas a uma melhor gestão como também à criação de inovação em si. Para tanto, foi considerada como embasamento para obtenção dos dados para análise, principalmente, o instrumento de medição disposto na publicação "O desafio da Gestão do Conhecimento nas áreas de administração e planejamento das 
Instituições Federais de Ensino Superior (IFES)" cujo objetivo é divulgar resultados de estudos direta ou indiretamente desenvolvidos pelo Instituto de Pesquisa Econômica Aplicada (Ipea), onde o autor analisou a situação atual da implantação de práticas de gestão do conhecimento em 45 instituições.

\section{FUNDAMENTAÇÃO TEÓRICA}

\subsection{PRÁTICAS DE GESTÃO DO CONHECIMENTO}

Antes de se aprofundar nos conceitos de GC, é necessário estabelecer a constituição do conhecimento em si, que se diferencia na literatura da área do conceito de dados e informações. Setzer (2014, não paginada) traz em seu estudo que:

Um dado é puramente objetivo - não depende do seu usuário. A informação é objetiva-subjetiva no sentido que é descrita de uma forma objetiva (textos, figuras, etc.) ou captada a partir de algo objetivo, como no exemplo de se estender o braço para fora da janela para ver se está frio, mas seu significado é subjetivo, dependente do usuário. $O$ conhecimento é puramente subjetivo - cada um tem a vivência de algo de uma forma diferente.

Dessa forma, vincula-se o conhecimento ao seu portador enquanto representação da soma das experiências de uma pessoa e/ou organização, estabelecendo-se que esse conceito se refere a algo que existe na mente humana e que exige análise, síntese, reflexão e contextualização (ALVARENGA NETO, 2005).

É consenso entre os diversos estudiosos, de que o conhecimento reside no capital intelectual das pessoas que vem do resultado da experiência humana e de suas reflexões, baseadas em crenças e experiências que são ao mesmo tempo, individuais e coletivas. Isso faz com que os profissionais passem a ser considerados ativos decisivos para o sucesso de suas organizações, visto que, na gestão contemporânea, são os ativos intangíveis, constituídos pelo conhecimento, que triunfam. (MAGNANI e HERBELÊ, 2010).

A importância do conhecimento é também reforçada por Probst et. al. (2012, p. 16) quando reiteram que "Se uma empresa com uma base de conhecimento bem 
desenvolvida operar em um ambiente intensivo em conhecimento, é provável que suas competências específicas desenvolvam uma dinâmica própria, criando, dessa forma, novas oportunidades estratégicas".

Nesse contexto, surge a importância da GC conforme estabelecem Strauhs et. al. (2012, p. 55) quando afirmam que esse modelo de gestão vem para "[...] proporcionar condições para criar, adquirir, organizar e processar informações estratégicas e, assim, gerar benefícios [...]". Segundo os autores mais do que apenas criar conhecimento, gestores devem buscar transformá-los em resultados práticos.

Assim, a GC está intrinsecamente ligada à como o conhecimento detido nas pessoas que compõem a organização pode ser gerido para trazer respostas a resoluções de situações que envolvem o aspecto geral em que estão inseridos, sendo importante ressaltar que, conforme evidenciam Magnani e Heberlê (2010), a GC não está diretamente ligada a necessidade de implementação de sistemas de tecnologia da informação, mas de processos de capacitação para a produção do conhecimento.

Strauhs et. al. (2012) apresentam que dentro da gestão do conhecimento se lida com dois conceitos diferentes, o conhecimento tático e o explícito, sendo o tácito aquele que é individual, frequentemente não gerenciável, e que se torna público, ou seja, explícito, por meios de processos de conversão amplamente discutidos academicamente.

Magnani e Heberlê (2010) nos trazem que a construção do conhecimento tácito, ou seja, aquele que é individual, está diretamente ligado a experiência do indivíduo. Segundo os autores:

O segredo para aquisição do conhecimento tácito é a experiência. Sem alguma forma de experiência compartilhada é extremamente difícil para uma pessoa projetar-se no processo de raciocínio de outro indivíduo. A mera transferência de informações não faz sentido se estiver desligada das emoções associadas e dos contextos específicos nos quais as experiências compartilhadas se referem. Portanto, o processo de socialização é imprescindível para externalizar e transferir o conhecimento tácito (MAGNANI e HEBERLÊ, 2010, p. 78). 
Dessa forma, para que o conhecimento tácito seja alcançado por um indivíduo é indispensável que ele participe de alguma experiência prática para a construção daquele conhecimento, ou seja, para que aprenda pela aplicação. Strauhs et. al. (2012, p. 37) reforçam a importância de uma gestão do conhecimento tácito ao afirmar que:

Colaboradores com capacidade de melhorar o conhecimento tácito incrementam também seu processo de explicitação, ou seja, sua capacidade de compartilhar com outros indivíduos o próprio conhecimento, pois entendem que o compartilhamento faz crescer não só o ambiente organizacional como o seu próprio universo, em um ciclo vicioso.

Os autores Takeuchi e Nonaka (2008 apud MÜLLER et. al., 2015) apresentam um modelo que busca a conversão do conhecimento tácito dos indivíduos para conhecimento explícito por meio do processo $\mathrm{SECl}$, que contém as etapas de Socialização, Externalização, Combinação e Internalização do conhecimento. Sendo:

a) Socialização: compartilhamento e criação de conhecimento tácito através de experiência direta que um indivíduo adquire de indivíduo, ou seja, de conhecimento tácito para conhecimento tácito;

b) Externalização: articulação de conhecimento tácito através do diálogo e da reflexão, ou seja, não possui o caráter experimentativo. A externalização ocorre de indivíduo para grupo, de conhecimento tácito para explícito;

c) Combinação: sistematização e aplicação do conhecimento e da informação, ocorrendo de um grupo de pessoas para a organização, com um objetivo definido. A combinação é feita de conhecimento explícito para conhecimento explícito;

d) Internalização: aprendizado e aquisição do novo conhecimento tácito a partir de prática organizacional, ou seja, a internalização ocorre de organização para indivíduo e é feita de conhecimento explícito para conhecimento tácito.

Dessa forma, é importante que o conhecimento assuma um ciclo dentro da organização, para garantir que sua criação e disseminação estejam continuamente 
gerando efeitos positivos. Strauhs et. al. (2012) afirmam que o ambiente é fator decisivo para o estímulo ao compartilhamento o conhecimento, sobretudo quando aponta que:

Além de ser permeado pela confiança, o ambiente propício ao conhecimento deve ser estimulado pela crença de que o compartilhamento do conhecimento permite seu crescimento exponencial. Esse ambiente deve contar ainda com tecnologias informacionais que permitam aos indivíduos conectarem-se ao mundo à sua volta e, também, a políticas gerenciais que independam de pessoas serem adeptas ou não da construção contínua do conhecimento (STRAUHS et. al., 2012, p. 52).

A respeito de tecnologias informacionais e práticas que visem um bom funcionamento da GC, apresenta-se o Quadro 1 onde consta uma lista de 22 práticas de GC que foi elaborada a partir de exemplos concretos observados em organizações de todo o mundo, englobando aplicações práticas, técnicas, processos e ferramentas, adaptada da publicação "O Desafio da gestão do conhecimento nas áreas de administração e planejamento das Instituições federais de Ensino Superior (IFES)":

Quadro 1 - Práticas de gestão do conhecimento nas áreas de planejamento e administração

Ação ou Prática

Sistemas de workflow

\section{Definição}

Controle de qualidade da informação apoiado pela automação do fluxo ou do trâmite de documentos. Workflow é o termo utilizado para descrever a automação de sistemas e dos processos de controle interno, implantada para simplificar e agilizar o estabelecimento de parcerias, convênios, contratos que envolvam recursos financeiros ou não. É utilizado para controle de documentos e revisões, requisições de pagamentos, estatísticas de desempenho de funcionários, etc. 
Melhores práticas

Data warehouse (ferrame
de TI para apoio à GC)

Identificação e difusão de melhores práticas, que podem ser definidas como um procedimento validado para a realização de uma tarefa ou para a solução de um problema. Inclui o contexto no qual pode ser aplicado. São documentadas por meio de bancos de dados, manuais ou diretrizes.

Tecnologia de rastreamento de dados com arquitetura hierarquizada disposta em bases relacionais, que permite versatilidade na manipulação de grandes massas de dados.

Data mining (ferramenta de Os mineradores de dados são instrumentos com TI para apoio à GC) alta capacidade de associação de termos, o que Ihes permite "garimpar" assuntos ou temas específicos.

Comunidades

prática/comunidades conhecimento

de Grupos informais e interdisciplinares de pessoas de unidas em torno de um interesse comum. As comunidades são auto organizadas de modo que permita a colaboração de pessoas internas ou externas à organização; propiciem o veículo e o contexto para facilitar a transferência de melhores práticas e o acesso a especialistas, bem como a reutilização de modelos, do conhecimento e das lições aprendidas.

Mentoring Modalidade de gestão do desempenho na qual um expert participante (mentor) modela as competências de um indivíduo ou grupo, observa e analisa o desempenho, e retroalimenta a execução das atividades do indivíduo ou do grupo.

Coaching Similar ao mentoring, mas o coach não participa da execução das atividades. Faz parte de processo planejado de orientação, apoio, diálogo e 


\begin{tabular}{|c|c|}
\hline & $\begin{array}{l}\text { acompanhamento, alinhado às diretrizes } \\
\text { estratégicas. }\end{array}$ \\
\hline $\begin{array}{l}\text { Benchmarking interno e } \\
\text { externo }\end{array}$ & $\begin{array}{l}\text { Busca sistemática das melhores referências para } \\
\text { comparação aos processos, produtos e serviços } \\
\text { da organização. }\end{array}$ \\
\hline $\begin{array}{l}\text { Fóruns (presenciais e } \\
\text { virtuais) /listas de discussão }\end{array}$ & $\begin{array}{l}\text { Espaços para discutir, homogeneizar e partilhar } \\
\text { informações, ideias e experiências que } \\
\text { contribuirão para o desenvolvimento de } \\
\text { competências e para o aperfeiçoamento de } \\
\text { processos e atividades da instituição. }\end{array}$ \\
\hline $\begin{array}{l}\text { Mapeamento ou auditoria do } \\
\text { conhecimento }\end{array}$ & $\begin{array}{l}\text { Registro do conhecimento organizacional sobre } \\
\text { processos, produtos, serviços e relacionamento } \\
\text { com os clientes. Inclui a elaboração de mapas ou } \\
\text { de árvores de conhecimento, descrevendo fluxos e } \\
\text { relacionamentos de indivíduos, de grupos ou a } \\
\text { organização como um todo. }\end{array}$ \\
\hline $\begin{array}{l}\text { Ferramentas de } \\
\text { colaboração, como portais, } \\
\text { intranets e extranets }\end{array}$ & $\begin{array}{l}\text { Portal ou outros sistemas informatizados que } \\
\text { capturam e difundem conhecimento e experiência } \\
\text { entre trabalhadores/departamentos. Um portal é } \\
\text { um espaço web de integração dos sistemas } \\
\text { corporativos, com segurança e privacidade dos } \\
\text { dados. O portal pode constituir-se em um } \\
\text { verdadeiro ambiente de trabalho e repositório de } \\
\text { conhecimento para a organização e seus } \\
\text { colaboradores, propiciando acesso a todas as } \\
\text { informações e aplicações relevantes, e também } \\
\text { como plataforma para comunidades de prática, } \\
\text { redes de conhecimento e melhores práticas. Nos } \\
\text { estágios mais avançados permite customização e } \\
\text { personalização da interface para cada um dos } \\
\text { servidores. }\end{array}$ \\
\hline
\end{tabular}




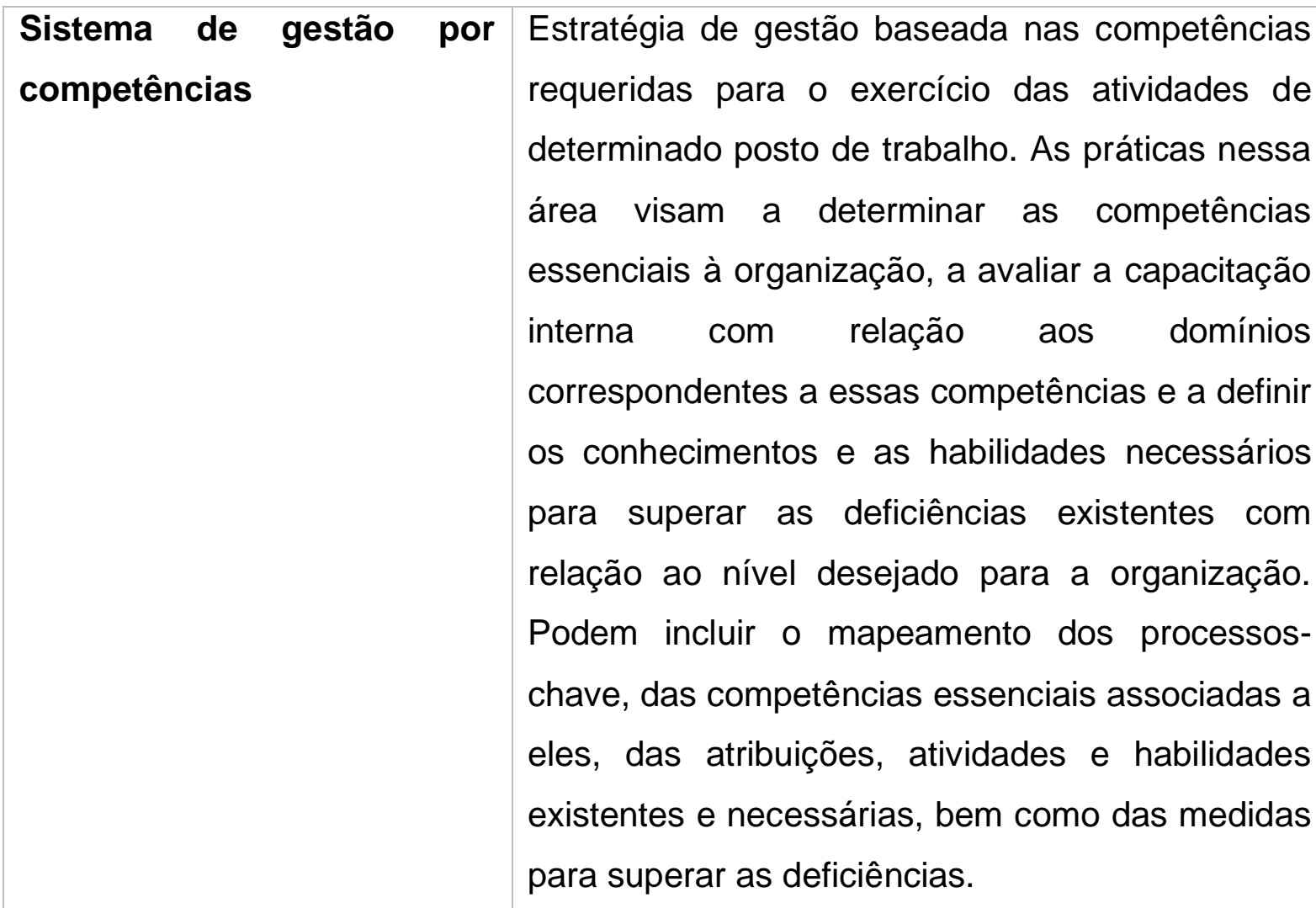

Banco de competências Repositório de informações sobre a capacidade individuais/banco de técnica, científica, artística e cultural das pessoas. talentos páginas amarelas A forma mais simples é uma lista on-line do pessoal, com um perfil da experiência e das áreas de especialidade de cada usuário. O perfil pode ser limitado ao conhecimento obtido por meio do ensino formal e dos eventos de treinamento e aperfeiçoamento reconhecidos pela instituição, ou pode mapear, de forma mais ampla, a competência dos funcionários, incluindo informações sobre conhecimento tácito, experiências e habilidades negociais e processuais.

Banco de competências Repositório de informações sobre a localização de organizacionais conhecimentos na instituição, incluindo fontes de consulta e também as pessoas ou as equipes detentoras de determinado conhecimento. 


\begin{tabular}{|c|c|}
\hline $\begin{array}{l}\text { Memória } \\
\text { organizacional/lições } \\
\text { aprendidas/banco de } \\
\text { conhecimentos }\end{array}$ & $\begin{array}{l}\text { Registro do conhecimento organizacional sobre } \\
\text { processos, produtos, serviços e relacionamento } \\
\text { com os usuários. As lições aprendidas são relatos } \\
\text { de experiências nos quais se registra o que } \\
\text { aconteceu, o que se esperava que acontecesse, a } \\
\text { análise das causas das diferenças e o que foi } \\
\text { aprendido durante o processo. A gestão de } \\
\text { conteúdo mantém atualizadas as informações, } \\
\text { ideias, experiências, lições aprendidas e melhores } \\
\text { práticas documentadas na base de } \\
\text { conhecimentos. }\end{array}$ \\
\hline $\begin{array}{l}\text { Sistemas de inteligência } \\
\text { organizacional } \\
\text { /empresarial/inteligência } \\
\text { competitiva }\end{array}$ & $\begin{array}{l}\text { Transformação de dados em inteligência com o } \\
\text { objetivo de apoiar a tomada de decisão. Visam a } \\
\text { extrair inteligência de informações, por meio da } \\
\text { captura e da conversão das informações em } \\
\text { diversos formatos, e à extração do conhecimento } \\
\text { a partir da informação. O conhecimento obtido de } \\
\text { fontes internas ou externas, formais ou informais, } \\
\text { é formalizado, documentado e armazenado para } \\
\text { facilitar o seu acesso. }\end{array}$ \\
\hline Educação corporativa & $\begin{array}{l}\text { Processos de educação continuada estabelecidos } \\
\text { com vistas à atualização do pessoal de maneira } \\
\text { uniforme em áreas da instituição. Pode ser } \\
\text { implementada sob a forma de universidade } \\
\text { corporativa, sistemas de ensino a distância, etc. }\end{array}$ \\
\hline Universidade corporativa & $\begin{array}{l}\text { Constituição formal de unidade organizacional } \\
\text { dedicada a promover a aprendizagem ativa e } \\
\text { contínua dos colaboradores da organização. } \\
\text { Programas de educação continuada, palestras e } \\
\text { cursos técnicos visam a desenvolver tanto os } \\
\text { comportamentos, as atitudes, os e conhecimentos }\end{array}$ \\
\hline
\end{tabular}




\begin{tabular}{|c|c|}
\hline & $\begin{array}{l}\text { mais amplos como as habilidades técnicas mais } \\
\text { específicas. }\end{array}$ \\
\hline $\begin{array}{l}\text { Gestão do capital } \\
\text { intelectual/gestão dos ativos } \\
\text { intangíveis }\end{array}$ & $\begin{array}{l}\text { Os ativos intangíveis são recursos disponíveis no } \\
\text { ambiente institucional, de difícil qualificação e } \\
\text { mensuração, mas contribuem para os seus } \\
\text { processos produtivos e sociais. A prática pode } \\
\text { incluir mapeamento dos ativos organizacionais } \\
\text { intangíveis, gestão do capital humano, política de } \\
\text { propriedade intelectual. }\end{array}$ \\
\hline Narrativas & $\begin{array}{l}\text { Técnicas utilizadas em ambientes de gestão do } \\
\text { conhecimento para descrever assuntos } \\
\text { complicados, expor situações e/ou comunicar } \\
\text { lições aprendidas, ou, ainda, interpretar mudanças } \\
\text { culturais. São relatos retrospectivos de pessoal } \\
\text { envolvido nos eventos ocorridos. }\end{array}$ \\
\hline Gestão de conteúdo & $\begin{array}{l}\text { Representação dos processos de seleção, } \\
\text { captura, classificação, indexação, registro e } \\
\text { depuração de informações. Envolve, tipicamente, } \\
\text { pesquisa contínua dos conteúdos dispostos em } \\
\text { instrumentos, como base de dados, árvores de } \\
\text { conhecimento, redes humanas, etc. }\end{array}$ \\
\hline $\begin{array}{l}\text { Gestão eletrônica } \\
\text { documentos (GED) }\end{array}$ & $\begin{array}{l}\text { Prática de gestão que implica adoção de } \\
\text { aplicativos informatizados de controle de emissão, } \\
\text { edição e acompanhamento da tramitação, da } \\
\text { distribuição, do arquivamento e do descarte de } \\
\text { documentos. }\end{array}$ \\
\hline
\end{tabular}

Fonte: adaptado de Batista, 2006 em "O Desafio da gestão do conhecimento nas áreas de administração e planejamento das Instituições federais de Ensino Superior (IFES)". 
Dessa forma, entende-se que as instituições que adotam essas práticas em seu cotidiano contribuem para um bom fluxo do conhecimento entre seus colaboradores, ao passo que abrangem os processos de criação, transferência e aplicação do conhecimento, garantindo assim usufruir dos benefícios oferecidos pela GC dentro das organizações, como melhor gestão de processos internos e intensificação dos processos inovativos.

\subsection{GESTÃO DO CONHECIMENTO NA ADMINISTRAÇÃO PÚBLICA}

No século XXI a economia do conhecimento globalizado traz novas demandas que mudam tanto as perspectivas de gestão de negócios quanto às de governo de países e cidades (WIIG, 2011). Vivemos em um mundo de mudanças rápidas e constantes guiadas pela globalização, onde uma economia baseada no conhecimento traz não apenas desafios, como também oportunidades, tanto para a área privada quanto a pública, de forma que se pode afirmar que uma efetiva aquisição e disseminação de conhecimento são, sobretudo, fortes fatores para um bom funcionamento das funções do governo (CONG e PANDYA, 2003).

Para que essas oportunidades sejam aproveitadas é necessário buscar a integração e a criação de uma cultura participativa na organização, onde cada um e o todo se interessem em colaborar para a criação de um ambiente propício à inovação e ao aprendizado contínuo, buscando e espalhando o caráter do conhecimento não apenas para benefício da organização, como também para o próprio crescimento profissional das pessoas ligadas a esse processo (FIGUEIREDO, 2005 apud LIMA et. al. 2014).

A administração pública, num aspecto geral, tem a responsabilidade de assegurar que a área sobre sua abrangência terá sempre a habilidade de não apenas manter como melhorar a qualidade de vida que pretende oferecer a seus cidadãos, isso significa, dentre outros fatores, manter a força de trabalho daquela região competitiva o suficiente para estar apta a se completar na economia regional e também global. Essas situações são bem conhecidas pelos administradores públicos, e é nesse contexto que o campo da gestão do conhecimento introduz novas opções, capacidades e práticas que podem impactar e auxiliar a administração pública a obter 
vantagens, sendo assim, também se torna uma nova responsabilidade da administração pública gerir um conhecimento capaz de fortalecer a efetividade dos serviços públicos e melhorar a vivência da sociedade (WIIG, 2000).

Além disso, quando se pensa na GC como uma forma de abordagem inserida no contexto interno de um órgão público, Batista (2012, p. 43) traz a importância de suas práticas ao ressaltar que essa gestão pode ser utilizada "[...] para aumentar a capacidade organizacional e alcançar a excelência em gestão pública por meio da melhoria dos processos internos, desenvolvimento de competências essenciais e planejamento de estratégias inovadoras." Assim, pode-se afirmar que, na administração pública, uma efetiva GC ajuda no enfrentamento de desafios e resoluções de situações ao implementar práticas inovadoras de gestão e melhorar a qualidade do serviço público em benefício dos cidadãos, que são seus usuários, e assim da sociedade como um todo (BATISTA, 2012).

Em questão de aplicabilidade da GC é necessário ressaltar que as pessoas envolvidas desempenham um papel importante, por isso, a organização pública deve investir em capacitação e desenvolvimento de carreiras visando incrementar a habilidade dos servidores e gestores públicos de identificar, criar, armazenar e aplicar conhecimento. Considerando que o conjunto de capacidades individuais dos servidores públicos de uma equipe é o que contribui para aumentar a capacidade da equipe como um todo, pode-se afirmar que quando os servidores de uma equipe estão constantemente aprendendo e compartilhando conhecimento entre eles, há um aumento na capacidade de realização da equipe de trabalho (BATISTA, 2012).

Em seu estudo a respeito da GC no Instituto Federal de Educação, Ciência e Tecnologia do Maranhão, Lima et. al (2014, p. 107) trazem a instituição como um relevante objeto de estudo, uma vez que:

O Instituto Federal, como instituição de ensino, produz conhecimentos diariamente, que apesar de sua importância, muitas vezes se perde na burocracia, e em plena era da tecnologia da informação, tem-se observado que o conhecimento apropriado pelos servidores, fragiliza-se, em face desse novo contexto que se apresenta. Nesse contexto, o desafio de produzir mais e melhor, assim como o desafio de prestar um 
serviço de qualidade à população vai sendo suplantado pelo desafio permanente de criar novos produtos, serviços, processos e sistemas gerenciais.

Assim, pode-se afirmar que apesar de todo seu contexto envolvido no meio empresarial das instituições privadas, a gestão do conhecimento possui potencial de ser uma aliada fundamental para os setores da área pública, pois suas práticas são capazes de gerar benefícios internos em diversos âmbitos que afetarão positivamente o resultado final, que é oferecer qualidade de produtos e serviços públicos para a sociedade.

\subsection{GESTÃO DO CONHECIMENTO EM INCUBADORAS}

Uma incubadora de empresa pode ser definida como um ambiente que visa oferecer suporte a empreendedores para que eles possam desenvolver ideias inovadoras, normalmente em fases iniciais, e transformá-las em empreendimentos prontos para entrar no mercado, para isso, oferece infraestrutura e suporte gerencial, orientando os empreendedores quanto à gestão do negócio e sua competitividade (ANPROTEC, 2019).

Depiné e Teixeira (2018) trazem em seu livro "Habitats de Inovação: conceito e prática" um estudo a respeito da relevância das incubadoras do ponto de vista de diversos autores, trazendo-as como um dos principais habitats de inovação, pois são capazes de fornecer condições e facilidades necessárias para o surgimento e crescimento de novas empresas e negócios, alavancando fatores econômicos e o desenvolvimento da cultura empreendedora na conjuntura em que estão inseridas.

Atualmente muitas instituições de ensino têm adotado a vinculação a esses ambientes de inovação visando alavancar os projetos de seus estudantes e estimulá-los na prática do empreendedorismo, isso é viável a partir do momento que se considera que esse tipo de instituição tem certa responsabilidade na criação de conhecimento, o que é reiterado por Martins et. al. (2006, p. 1) quando destacam que:

São incubadoras que abrigam empreendimento para as quais o conhecimento é o principal insumo e que comercializam produtos com 
alto valor agregado. Este tipo de incubadora, preferencialmente, localizase próxima a universidades ou centros de pesquisa. Assim, podem aproveitar a mão-de-obra altamente especializada e, de maneira oportuna, podem despertar o espírito empreendedor nos alunos e pesquisadores dessas entidades.

Dessa forma, destaca-se a importância de incubadoras ligadas a instituições de ensino, visto que, conforme frisam Fiala e Andreassi (2013, p. 760), "Na busca por novas metodologias e elementos para o ensino e estímulo ao empreendedorismo, as incubadoras de negócios aparecem como um ambiente que poderia ser explorado mais intensamente para esse fim".

A importância das incubadoras está intrinsecamente ligada ao desenvolvimento da economia de onde se inserem, visto que o estímulo ao empreendedorismo agrega também estímulos em áreas desse setor. Isso é corroborado com o disposto por Silva (2009, p. 246) quando afirma que:

As incubadoras contribuem para a promoção do empreendedorismo, do desenvolvimento econômico-regional, da geração de empregos, do desenvolvimento tecnológico e da diversificação econômico-regional, oferecendo produtos e serviços inovadores. Seus principais estimuladores acreditam que elas são uma opção inteligente e apropriada para promover o desenvolvimento socioeconômico local e nacional. Proporcionam, portanto, duas motivações de naturezas distintas: econômica e social.

Logo, pode-se afirmar que as incubadoras de empresas já são parte do cotidiano empreendedor e em sua atuação lidam com organizações e ambientes complexos, voltados para a inovação e com forte utilização de conhecimento como matéria prima de seus processos, produtos e serviços. (MÜLLER et. al., 2015).

Portanto, compreendendo-se a relevância das incubadoras e também o seu papel na criação de conhecimento através da necessidade de serem inovadoras, entra-se no contexto da gestão do conhecimento dentro desses ambientes, sobretudo, para que o conhecimento possa chegar às pessoas envolvidas nos empreendimentos dos quais essas incubadoras são responsáveis. Raupp (2010, p. 193) confirma essa visão ao trazer que: 
Por ser um ambiente onde são gerados conhecimentos, os gestores das incubadoras precisam canalizá-los, através dos empreendedores, para que possam ser difundidos e desenvolvidos por meio de novas unidades de negócio.

Considera-se, assim, que a GC e suas práticas de desenvolver soluções e inovações podem contribuir de forma significativa quando aplicada no contexto das incubadoras de empresas, não apenas na forma como gere seus processos internos, como também na construção e disseminação do conhecimento para sua comunidade.

\subsection{A ATIVA INCUBADORA DE EMPRESAS DO IFMT}

A Ativa Incubadora é um programa oferecido pelo IFMT para empreendedores tradicionais ou solidários que desejam desenvolver produtos ou serviços inovadores, contando com apoio técnico, gerencial, físico e tecnológico do IFMT e das instituições parceiras, com finalidade de torná-los empreendimentos inovadores de sucesso e sustentáveis. Sua área de incubação e atuação inicialmente era voltada para IFMT campus São Vicente e agora se encontra com gerência na reitoria e com núcleos presentes em vários campi do estado, passando por planejamento de reestruturação para viabilizar sua atuação em todos, contribuindo na promoção do desenvolvimento regional. (IFMT, 2019)

Em 28/04/2015, conforme Resolução CONSUP № 06 de 28/04/2015, a Ativa teve sua gestão inserida nas atividades do Eixo: Empreendedorismo da Pró-reitoria de Extensão, tendo ampliado seus objetivos e potencializado sua atuação, e hoje se define como um "Programa vinculado à Pró-reitoria de Extensão, criado com o objetivo de promover empreendimentos inovadores, oferecendo suporte a empreendedores para que eles possam desenvolver ideias inovadoras e transformá-las em empreendimentos de sucesso." (IFMT, 2019).

Dessa forma, a Ativa Incubadora hoje possui sua Gerência Executiva localizada na reitoria do instituto, em Cuiabá, mas sua atuação contempla várias regiões do estado através dos núcleos locais que podem ser abertos em cada campus. A Imagem 1 
retirada do site da Ativa Incubadora demonstra a disposição dos núcleos atualmente no estado:

Imagem 1 - A Ativa Incubadora de Empresas do IFMT

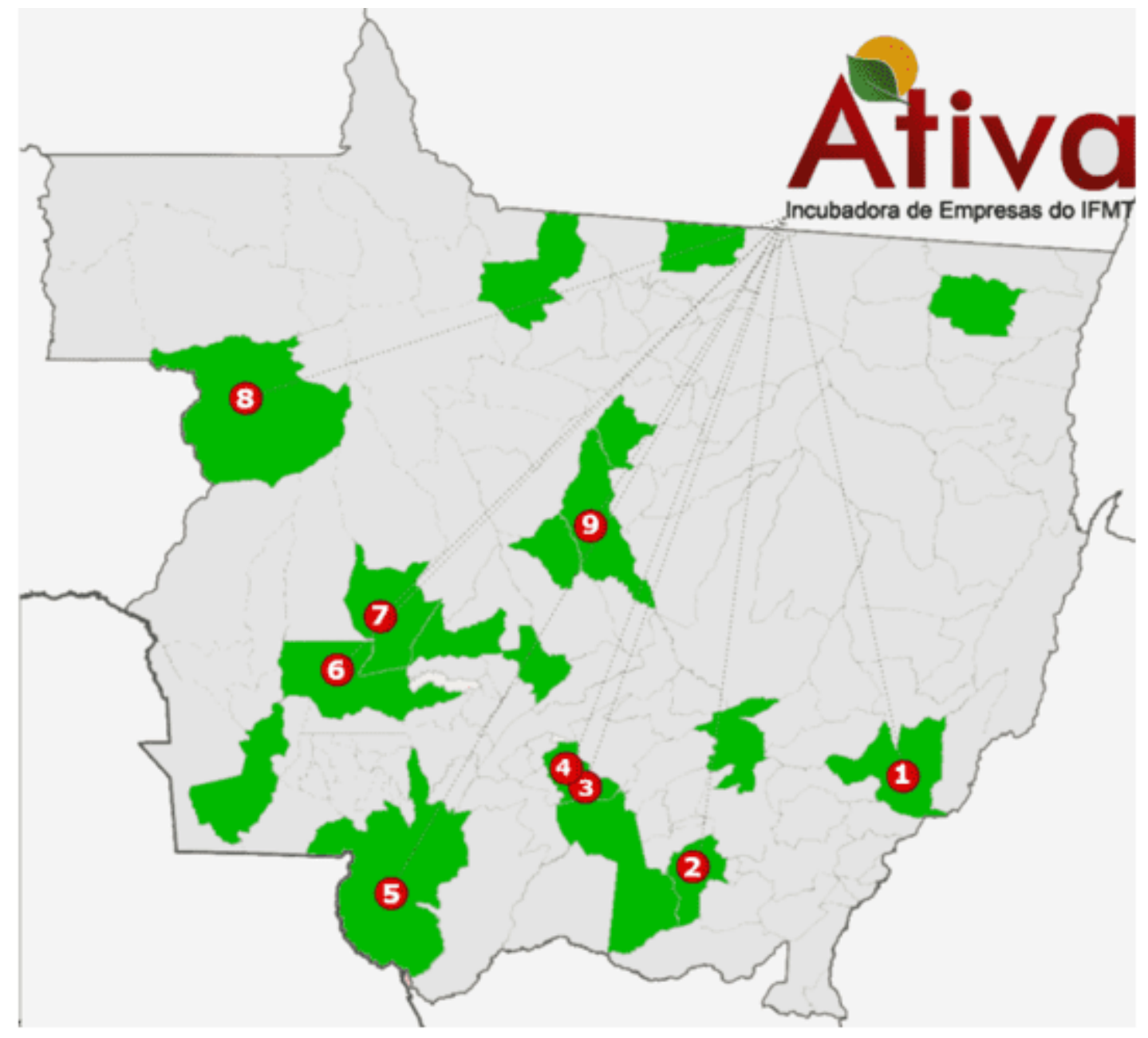

Fonte: Ativa, 2019.

Conforme demonstrado na Imagem 1, a Ativa em 2019 se estendia em 9 núcleos espalhados por todo o estado de Mato Grosso, sendo: 1) Campus Barra do Garças; 2) Campus Rondonópolis; 3) Campus Cuiabá Bela Vista; 4) Campus Cuiabá Octayde;

5) Campus Cáceres; 6) Campus Avançado Tangará da Serra; 7) Campus Campo Novo do Parecis; 8) Campus Juína; e 9) Campus Sorriso.

O artigo 4ํㅡㄹ do Regimento Interno da Ativa Incubadora de Empresas do IFMT traz como missão da incubadora "difundir a cultura empreendedora no âmbito do Instituto federal 
de Mato Grosso, fomentando e apoiando a geração de empreendimentos de Economia criativa e de Economia Solidária, desenvolvendo e ofertando ao mercado, produtos e serviços competitivos e diferenciados." (IFMT, 2017, p. 1).

\subsubsection{DA ESTRUTURA DA ATIVA INCUBADORA}

Numa análise do Regimento Interno da Ativa Incubadora de Empresas, apresenta-se a seguir o Quadro 2 com a ordem hierárquica estrutural:

Quadro 2 - Hierarquia Estrutural da Ativa Incubadora de Empresas do IFMT

\begin{tabular}{|c|c|c|c|}
\hline Nome & Local & Composição & Definição \\
\hline $\begin{array}{l}\text { Conselho } \\
\text { Deliberativo }\end{array}$ & $\begin{array}{l}\text { Sede } \\
\text { Gerencial/Reitoria }\end{array}$ & $\begin{array}{l}\text { Reitor (presidente), } \\
\text { Pró-reitor de Extensão, } \\
\text { Pró-reitor de Pesquisa } \\
\text { e Inovação, Pró-reitor } \\
\text { de Administração, } \\
\text { Diretor de Extensão, } \\
\text { Gerência Executiva, } \\
\text { Coordenador do Núcleo } \\
\text { de Inovação } \\
\text { Tecnológica. }\end{array}$ & $\begin{array}{l}\text { Órgão máximo de } \\
\text { decisão no âmbito da } \\
\text { Ativa Incubadora de } \\
\text { Empresas, } \\
\text { constituindo-se } \\
\text { também em espaço } \\
\text { de estudo e } \\
\text { elaboração de } \\
\text { conhecimentos } \\
\text { voltados à ação do } \\
\text { instituto junto aos } \\
\text { empreendimentos } \\
\text { incubados e às } \\
\text { empresas juniores. }\end{array}$ \\
\hline $\begin{array}{l}\text { Gerência } \\
\text { Executiva }\end{array}$ & $\begin{array}{l}\text { Sede } \\
\text { gerencial/Reitoria }\end{array}$ & $\begin{array}{l}\text { Servidor nomeado pelo } \\
\text { reitor do IFMT. }\end{array}$ & $\begin{array}{l}\text { Faz cumprir as } \\
\text { decisões, diretrizes e } \\
\text { normas estabelecidas } \\
\text { pelo Conselho } \\
\text { Deliberativo, para que }\end{array}$ \\
\hline
\end{tabular}




\begin{tabular}{|c|c|c|c|}
\hline & & & $\begin{array}{l}\text { sejam atingidos seus } \\
\text { objetivos. }\end{array}$ \\
\hline $\begin{array}{l}\text { Conselho } \\
\text { Gestor }\end{array}$ & $\begin{array}{l}\text { Núcleo Incubador } \\
\text { Local }\end{array}$ & $\begin{array}{l}\text { Diretor geral do campus } \\
\text { (presidente), } \\
\text { Diretor/Coordenador de } \\
\text { Extensão, } \\
\text { Diretor/Coordenador de } \\
\text { Pesquisa e Inovação, } \\
\text { Diretor/Chefe de } \\
\text { Departamento de } \\
\text { Administração } \\
\text { Planejamento, } \\
\text { Gerência local. }\end{array}$ & $\begin{array}{l}\text { Órgão máximo do } \\
\text { Núcleo Incubador da } \\
\text { Ativa no campus em } \\
\text { que está localizado. } \\
\text { Funciona como uma } \\
\text { extensão da Gerência } \\
\text { Executiva, } \\
\text { garantir } \\
\text { cumprimento das } \\
\text { diretrizes, políticas, } \\
\text { normas, regras e } \\
\text { procedimentos } \\
\text { estabelecidos. }\end{array}$ \\
\hline $\begin{array}{l}\text { Gerência } \\
\text { Local }\end{array}$ & $\begin{array}{l}\text { Núcleo Incubador } \\
\text { Local }\end{array}$ & $\begin{array}{l}\text { Um servidor nomeado } \\
\text { pelo Diretor geral do } \\
\text { campus. }\end{array}$ & $\begin{array}{l}\text { Órgão encarregado } \\
\text { por coordenar todas } \\
\text { as ações no Núcleo } \\
\text { Incubador da Ativa do } \\
\text { campus e promover } \\
\text { as condições } \\
\text { necessárias } \\
\text { realização dos seus } \\
\text { fins e objetivos, } \\
\text { negociando com as } \\
\text { instâncias do IFMT as } \\
\text { demandas e metas do } \\
\text { núcleo e coordenando } \\
\text { o andamento das } \\
\text { atividades no campus. }\end{array}$ \\
\hline
\end{tabular}




\begin{tabular}{|c|c|c|c|}
\hline $\begin{array}{l}\text { Comissão } \\
\text { Técnica }\end{array}$ & $\begin{array}{l}\text { Núcleo Incubador } \\
\text { Local }\end{array}$ & $\begin{array}{l}\text { Composta por } \\
\text { especialistas, } \\
\text { consultores, } \\
\text { pesquisadores } \\
\text { pessoas de notório } \\
\text { saber no tema da } \\
\text { proposta apresentada, } \\
\text { limitada ao mínimo de } \\
\text { três integrantes, } \\
\text { indicados } \\
\text { Gerência } \\
\text { podendo ser servidor } \\
\text { do IFMT, de instituições } \\
\text { parceiras e pessoas da } \\
\text { comunidade. }\end{array}$ & $\begin{array}{l}\text { Comissão } \\
\text { responsável por } \\
\text { auxiliar a Gerência } \\
\text { Local, participando do } \\
\text { processo de } \\
\text { elaboração de projeto } \\
\text { dos } \\
\text { empreendimentos, } \\
\text { organizando } \\
\text { desenvolvendo todas } \\
\text { as atividades relativas } \\
\text { ao processo de } \\
\text { incubação, também } \\
\text { socializando } \\
\text { atividades as } \\
\text { desenvolvidas } \\
\text { promovendo } \\
\text { discussões e estudos. }\end{array}$ \\
\hline
\end{tabular}

Fonte: adaptado de IFMT (2017), Regimento Interno da Ativa Incubadora de Empresas.

Através do Quadro 2 podemos perceber que embora as deliberações sejam, em sua maioria, responsabilidade de órgãos superiores, a execução das atividades da incubadora fica ligada de forma direta a Gerência Executiva, composta por servidor da reitoria, e aos gerentes locais de cada um dos núcleos dispostos pelos campi do estado, que são encarregados de garantir o cumprimento dessas atividades nos campi em que estão lotados.

Assim, podemos concluir que a estrutura da Ativa Incubadora de Empresas do IFMT garante a execução das suas atividades de forma funcional, através de uma composição que concentra as deliberações principais, mas de forma a garantir que 
cada núcleo consiga adaptar as deliberações para a realidade específica de seu campus através de uma gerência local.

\section{METODOLOGIA}

Este estudo objetivou mensurar percepções a respeito da Ativa Incubadora de Empresas através da análise de dados de sua Gerência Local e de cada um de seus núcleos durante o ano de 2019, sendo, portanto, um estudo de caso coletivo, conforme estipula Gil (2002, p. 139):

Estudo de caso coletivo é aquele cujo propósito é o de estudar características de uma população. Eles são selecionados porque se acredita que, por meio deles, torna-se possível aprimorar o conhecimento acerca do universo a que pertencem.

Para recolhimento dos dados analisados foi empregado um questionário com aspecto geral a respeito de GC para a Gerência Executiva da Ativa Incubadora na reitoria e questionário com aspectos específicos às práticas de GC para cada um dos gestores locais dos 9 núcleos pelo estado de Mato Grosso. O questionário foi enviado para os gestores locais dos 9 núcleos atuantes em 2019 tendo sido respondido por sete (Cuiabá, Bela Vista, Barra do Garças, Cáceres, Rondonópolis e Juína). Os núcleos dos campi que não responderam ao questionário informaram que embora estivessem constituídos, não tiveram oportunidade de desenvolver atividades naquele ano.

O questionário foi aplicado de duas formas, em um fórum em maio de 2020 onde se encontrou a maioria dos gestores e por e-mail para aqueles que não se encontravam presentes. Para a análise da percepção geral de GC na Gerência Executiva foi considerada uma análise qualitativa, ao passo que foram recolhidas seus entendimentos a respeito desse modelo de gestão, enquanto para a análise dos núcleos optou-se por uma abordagem quantitativa, onde eles informaram em qual estágio de implantação encontrava-se cada uma das 18 práticas de GC que foram apresentadas no questionário. Para este estudo, o questionário se embasou no instrumento de medição da publicação "O desafio da Gestão do Conhecimento nas 
áreas de administração e planejamento das Instituições Federais de Ensino Superior (IFES)" desenvolvidos por Batista (2006) pelo Ipea.

O diagnóstico das práticas de GC em relação aos núcleos levava em consideração desde aqueles que não possuíam planos de aplicação para determinada prática até aqueles onde a prática já estivesse implantada e gerando resultados, assim sendo possível mensurar tanto quais núcleos encontravam-se mais avançados em relação à GC, quanto quais eram as práticas que se encontram mais efetivas atualmente. Para a proposta de intervenção foi considerado o disposto na literatura a respeito de criação, transferência e gestão do conhecimento de acordo com os resultados obtidos no diagnóstico.

\section{ANÁLISE DOS DADOS}

Para a análise dos dados foi dividido primeiramente as perspectivas de GC no âmbito da gerência Executiva da Ativa Incubadora na reitoria do IFMT, e então considerado um panorama das práticas de GC dentro de cada núcleo, onde foram identificados tanto os núcleos que menos aderem as práticas, quanto quais são as práticas que possuem mais adesão entre eles.

\subsection{GESTÃO DO CONHECIMENTO NA GERÊNCIA EXECUTIVA DA ATIVA INCUBADORA}

A Gerência Executiva da Ativa é ocupada por servidor que trabalha na área de planejamento/administração há mais de 5 anos, estando a frente da incubadora por um período compreendido entre 2 a 3 anos e que informa ter conhecimento básico a respeito de Gestão do Conhecimento.

Em amplo aspecto, em relação a aplicabilidade da GC na Ativa Incubadora afirma que embora não seja uma das prioridades estratégicas da instituição, existe uma percepção de que é necessário ter alguma forma de gerir conhecimento. 
Isso demonstra certa fragilidade em relação à aplicabilidade das práticas de GC e do retorno tangível de resultados decorrentes dessas práticas, visto que, no momento em que a GC não é ainda aplicada em determinado ambiente organizacional, a sua implantação depende de ações intensivas, pois caracteriza mudanças comportamentais que vão influenciar o fluxo de processos de maneira holística, gerando assim uma barreira cultural conforme explicitado por Strauhs et. al. (2012, p. 13) ao definir essa mudança como um desafio em "[...] consolidar uma cultura da informação para que todos os colaboradores percebam e valorizem a importância do compartilhamento e uso da informação para gerar conhecimento e consequentemente produtos, serviços e processos inovadores."

Da mesma forma, a Gerência Executiva declara que a percepção de importância da GC dentro de sua instituição ainda não se refletiu na alocação de recursos, sejam eles humanos, financeiros ou de infraestrutura, refletindo mais uma fragilidade ao se tratar de um ambiente que, como ainda não possui nenhuma perspectiva de implantação formalizada de GC, dificilmente conseguirá implantá-la sem destacar recursos especificamente para essa finalidade.

Entretanto, mesmo que a GC em si não esteja formalizada, ressalta-se que isso não é impeditivo para que as práticas relativas a elas sejam implementadas, visto que quanto a "Melhores práticas" informou que se encontra como em fase de implantação. Quando questionada a respeito de sistemas de work-flowe ferramentas de Tecnologia da Informação (data warehouse e data mining) para apoio a GC, a gerência informou que não se aplicam a realidade atual da incubadora.

\subsection{DiAgnóstico E PROPOSTAS DE INTERVENÇÃo DAS PRÁTICAS DE GESTÃO DO CONHECIMENTO NOS NÚCLEOS DA ATIVA INCUBADORA}

A fim de preservar a identidade de cada campus, as amostras foram tratadas como de "A" a "G", conforme seguem sete respostas aos questionários. Inicialmente foi perguntado aos gestores dos núcleos há quanto tempo já trabalhavam na área de 
Gestão e Planejamento e quanto tempo estavam como gestores locais de seus núcleos, juntamente como uma pergunta acerca de qual era seu nível de familiaridade com o termo "Gestão do Conhecimento". Essa análise inicial dá-se a fim de verificar se as práticas de GC sofrem alguma influência de acordo com a experiência em gestão ou seu conhecimento da área em um aspecto geral.

Para cada prática de GC do questionário, eles deveriam optar por um dos cinco níveis de estágio de implantação daquela ação em seu núcleo, onde conforme o instrumento de medição que embasou este estudo, disposto na publicação "O desafio da Gestão do Conhecimento nas áreas de administração e planejamento das Instituições Federais de Ensino Superior (IFES)" que divulga resultados de estudos direta ou indiretamente desenvolvidos pelo Ipea, os estágios se referiam a: (0) Não existem planos de implantação, (1) Planejadas para o futuro, (2) Estão em processo de implantação, (3) Já estão implantadas e (4) Já estão implantadas e apresentando resultados importantes e relevantes.

Assim, consideramos a disposição no Quadro 3 a seguir, onde, avaliando 18 práticas de GC e as respostas de seus estágios de (0) a (4), efetuamos o somatório e a média das 18 respostas de cada núcleo para as respectivas práticas, dispondo primeiro aqueles núcleos que estivessem mais próximos da média "4", sendo assim os mais avançados na GC, para aqueles que estivessem com a média mais baixa.

Quadro 3 - Diagnóstico dos núcleos da Ativa Incubadora de acordo com o estágio de implantação de práticas de Gestão do Conhecimento:

\begin{tabular}{|c|c|c|c|c|c|c|c|c|}
\hline NÚCLEOS & $A$ & $B$ & C & D & $E$ & $F$ & $\mathrm{G}$ & Média do \\
\hline $\begin{array}{l}\text { Tempo de trabalho } \\
\text { na área de Gestão } \\
\text { e Planejamento: }\end{array}$ & $\begin{array}{l}2 \text { a } 3 \\
\text { anos }\end{array}$ & $\begin{array}{l}4 \text { a } \\
5 \\
\text { ano } \\
\mathrm{s}\end{array}$ & $\begin{array}{l}\text { Mai } \\
\text { s de } \\
5 \\
\text { ano } \\
\text { s }\end{array}$ & $\begin{array}{l}\text { Mais } \\
\text { de } 5 \\
\text { anos }\end{array}$ & $\begin{array}{l}\text { Mais } \\
\text { de } 5 \\
\text { anos }\end{array}$ & $\begin{array}{l}\text { Mais } \\
\text { de } 5 \\
\text { anos }\end{array}$ & $\begin{array}{l}\text { Mais } \\
\text { de } 5 \\
\text { anos }\end{array}$ & $\begin{array}{l}\text { estágio } \\
\text { de } \\
\text { implanta } \\
\text { ção da } \\
\text { prática }\end{array}$ \\
\hline $\begin{array}{l}\text { Tempo de Gestão } \\
\text { do Núcleo: }\end{array}$ & $\begin{array}{l}1 \text { a } 2 \\
\text { anos }\end{array}$ & $\begin{array}{ll}1 & a \\
2 & \end{array}$ & $\begin{array}{l}\text { Mai } \\
\text { s de }\end{array}$ & $\begin{array}{l}2 \text { a } 3 \\
\text { anos }\end{array}$ & $\begin{array}{l}1 \text { a } 2 \\
\text { anos }\end{array}$ & $\begin{array}{l}\text { Men } \\
\text { os }\end{array}$ & $\begin{array}{l}\text { Men } \\
\text { os }\end{array}$ & $\begin{array}{l}\text { de } \mathrm{GC} \\
\text { avaliada, }\end{array}$ \\
\hline
\end{tabular}




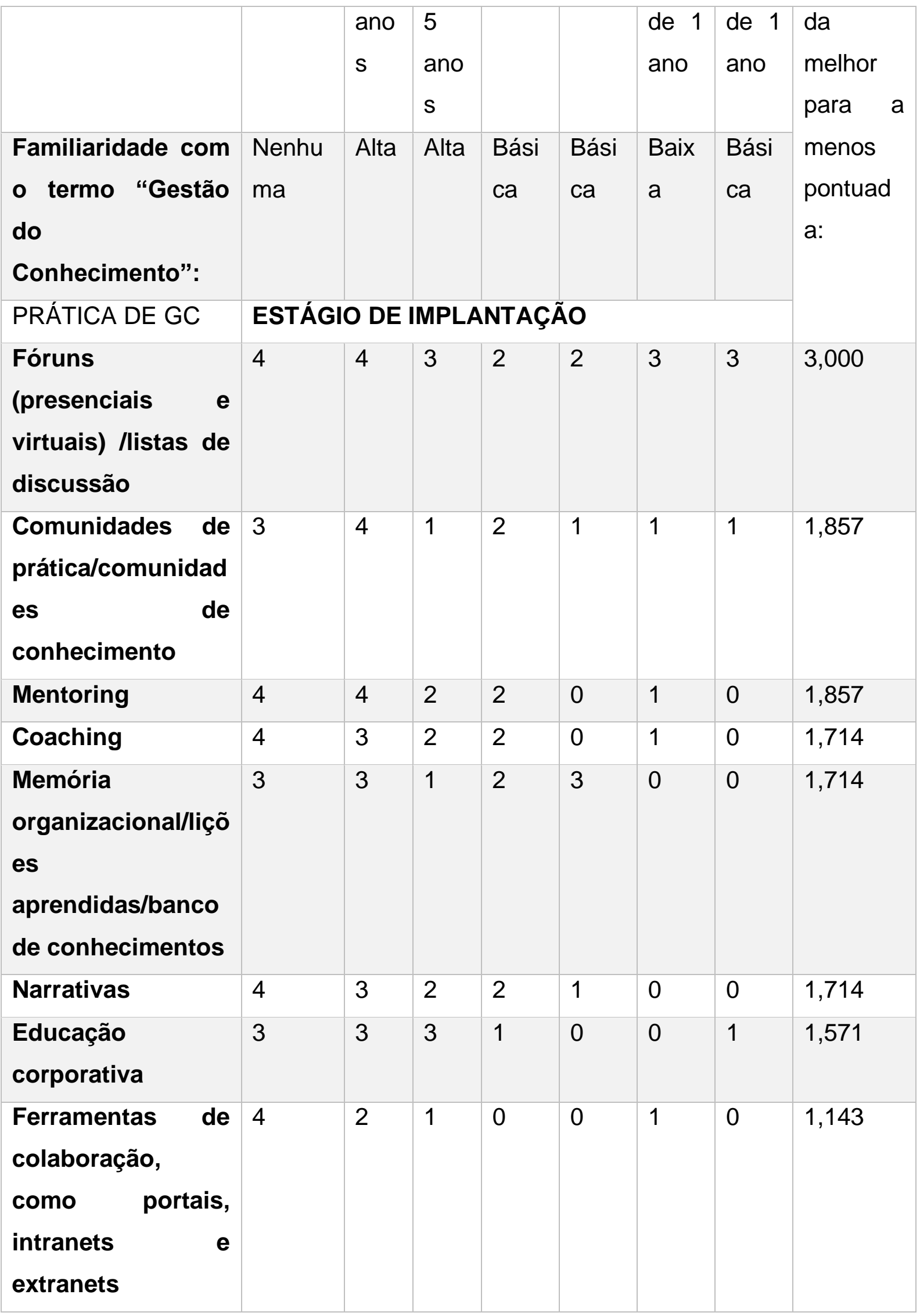




\begin{tabular}{|c|c|c|c|c|c|c|c|c|}
\hline $\begin{array}{l}\text { Gestão } \quad \text { de } \\
\text { conteúdo }\end{array}$ & 2 & 3 & 1 & 2 & 1 & 1 & 0 & 1,429 \\
\hline $\begin{array}{l}\text { Gestão do capital } \\
\text { intelectual/gestão } \\
\text { dos ativos } \\
\text { intangíveis }\end{array}$ & 4 & 2 & 1 & 1 & 1 & 0 & 0 & 1,286 \\
\hline $\begin{array}{l}\text { Gestão eletrônica } \\
\text { de documentos } \\
\text { (GED) }\end{array}$ & 4 & 4 & 1 & 0 & 0 & 0 & 0 & 1,286 \\
\hline $\begin{array}{l}\text { Benchmarking } \\
\text { interno e externo }\end{array}$ & 0 & 1 & 3 & 0 & 2 & 1 & 0 & 1,000 \\
\hline $\begin{array}{l}\text { Sistemas de } \\
\text { inteligência } \\
\text { organizacional } \\
\text { /empresarial/inteli } \\
\text { gência competitiva }\end{array}$ & 4 & 1 & 1 & 1 & 0 & 0 & 0 & 1,000 \\
\hline $\begin{array}{l}\text { Universidade } \\
\text { corporativa }\end{array}$ & 0 & 3 & 1 & 1 & 1 & 0 & 0 & 0,857 \\
\hline $\begin{array}{ll}\text { Mapeamento } & \text { ou } \\
\text { auditoria } & \text { do } \\
\text { conhecimento } & \end{array}$ & 1 & 2 & 1 & 0 & 0 & 0 & 1 & 0,714 \\
\hline $\begin{array}{l}\text { Banco de } \\
\text { competências } \\
\text { individuais/banco } \\
\text { de talentos } \\
\text { páginas amarelas }\end{array}$ & 3 & 0 & 1 & 0 & 0 & 0 & 0 & 0,571 \\
\hline $\begin{array}{l}\text { Banco de } \\
\text { competências } \\
\text { organizacionais }\end{array}$ & 0 & 0 & 1 & 0 & 0 & 0 & 0 & 0,286 \\
\hline $\begin{array}{l}\text { Sistema de gestão } \\
\text { por competências }\end{array}$ & 0 & 0 & 1 & 0 & 0 & 0 & 0 & 0,143 \\
\hline
\end{tabular}




\begin{tabular}{|l|l|l|l|l|l|l|l|}
\hline $\begin{array}{l}\text { Média do núcleo } \\
\text { avaliado, do melhor }\end{array}$ & 2,611 & 2,3 & 1,5 & 1,00 & 0,66 & 0,50 & 0,33 \\
$\begin{array}{l}\text { para o menos } \\
\text { pontuado: }\end{array}$ & 89 & 00 & 0 & 7 & 0 & 3 \\
\hline
\end{tabular}

Fonte: elaborado pelos autores.

Analisando disposto no Quadro 3, percebe-se que há relevância entre o nível de conhecimento do termo de "Gestão do Conhecimento" e a aplicação das práticas pelos gestores, uma vez que os núcleos $\mathrm{B}$ e $\mathrm{C}$, que responderam possuir familiaridade alta com o termo, encontram-se com melhores médias que a maioria, isso, entretanto, não sendo regra, uma vez que o núcleo $A$, sendo o único a responder que não possuía nenhuma familiaridade, ainda conseguiu a melhor média em relação à implantação das práticas. Outro padrão a ser observado é que aqueles núcleos onde seus gestores locais estavam há menos de 1 ano como responsáveis pela gestão foram os que apresentaram menores médias na implantação das práticas de GC.

Em uma análise de aspecto geral, podemos perceber que embora a maioria dos núcleos apresente média abaixo de 2,000 indicando uma baixa adesão as práticas de GC, o panorama das práticas em si e a percepção de suas importâncias não chega a ser desfavorável, ao passo que dos 126 estágios informados (considerando o estágio de cada uma das 18 práticas para cada um dos sete núcleos), apenas 48 foram apontados como estágio "(0) Não existem planos de implantação", o que confirma o disposto na literatura de que os ambientes de inovação em geral estão intrinsicamente ligados a geração e fluxo de conhecimento, e, portanto, acabam desenvolvendo percepções de como gerir esse conhecimento para garantir também que a inovação ocorra.

Entretanto, isso não anula o resultado de que a maioria das práticas de GC ainda não se encontra efetivamente aplicada ao contexto dos núcleos, visto que 50 dos estágios encontram-se entre "(1) Planejadas para o futuro" e "(2) Estão em processo de implantação", contra 16 estágios que se encontram no nível "(3) Já estão implantadas” 
e apenas 12 que se encontram no nível "(4) Já estão implantadas e apresentando resultados importantes e relevantes".

Para um diagnóstico mais preciso os dados também foram dispostos avaliando as médias de cada uma das 18 práticas de GC efetuando o somatório e a média das sete respostas para cada prática, dispondo primeiro aquelas que estivessem mais próximas da média "4", sendo assim as mais avançadas em estágios de implantação nos núcleos.

Assim, para analisar o caráter dessas práticas ressalta-se o disposto por Batista (2006) quando afirma que a gestão do conhecimento inicia-se com o processo de criação do conhecimento, ou seja, antes da execução do processo, quando as pessoas, com o objetivo de aprender antes de executar alguma ação buscam informações e conhecimentos de acordo com as melhores práticas, com a memória organizacional, ou nas lições aprendidas e no banco de conhecimentos, por meio de portais e intranets e também mediante a prática do benchmarking, observando-se que esse tipo de acesso só se dá quando conseguem eficaz alcance ao registro daquele conhecimento, que é a transformação do conhecimento tácito em explícito. Nesse momento é possível acessar também o banco de competências organizacionais e o banco de competências individuais/banco de talentos/páginas amarelas para identificar especialistas que possam vir a contribuir com os conhecimentos exigidos para o processo que se busca aferir. $O$ autor ainda afirma que é após a aplicação do conhecimento obtido que as informações estratégicas e os conhecimentos sobre os processos organizacionais podem ser transferidos e partilhados por meio de fóruns/listas de discussão, comunidades de práticas virtuais; educação corporativa; narrativas; mentoring e coaching.

Assim, percebe-se que os núcleos da Ativa Incubadora possuem boas práticas ao que se refere à transferência do conhecimento, com ótimo resultado em relação a fóruns (presenciais e virtuais) /listas de discussão e também uma boa disseminação das práticas de comunidades de prática/comunidades de conhecimento, mentoring, coaching, narrativas e educação corporativa. 
Isso é um diagnóstico extremamente relevante ao passo que, embora haja defasagem entre alguns núcleos em relação a outras práticas, quando há familiaridade com a transferência de conhecimento e seus processos contínuos de maneira a gerar uma socialização efetiva, é possível buscar um equilíbrio no nivelamento em relação ao que precisa ser melhorado através do maior estímulo e intensificação da transferência do conhecimento entre aqueles que já desenvolvem certas ações capazes de impactar positivamente dentro do âmbito do que se almeja melhorar.

Isso, entretanto, pode ter uma otimização não tão efetiva enquanto não houver clareza em relação a quem são aqueles indivíduos que podem, de fato, transferir o conhecimento que seja efetivo no ponto defasado. Essa clareza seria possível se houvesse entre os núcleos as práticas de banco de competências individuais/banco de talentos páginas amarelas, banco de competências organizacionais e um fluído sistema de gestão por competências, que são as práticas que se encontram com as menores médias.

Assim, embora para a transferência de conhecimento os núcleos possuam práticas que podem ser utilizadas a seu favor, neste momento, quando se precisar de um indivíduo específico para uma prática de transferência, como o mentoring ou o coaching, por exemplo, ainda haverá ruídos e morosidade na busca por quem seria o profissional mais capacitado dentro do tipo de conhecimento que se almeja socializar, o que poderia ser facilmente dirimido com a implantação de um banco de competências individuais/banco de talentos/páginas amarelas, por exemplo. Em relação à aplicabilidade desta prática como um catálogo de especialistas, Almeida et. al. (2016, p. 123) ressaltam que:

Essa prática, apesar de simples, é uma das mais úteis e necessárias a ser implementada, simplesmente pelo fato de identificar quem sabe o que dentro da organização. Na grande maioria das organizações, as pessoas detêm informação de quem sabe o que a partir da sua rede pessoal, que é bem limitada. Quando é implantado o catálogo de especialistas, as possibilidades se multiplicam, visto que podemos identificar competências em pessoas que jamais iríamos identificar se somente fosse utilizada a rede pessoal individual de cada um. 
Uma proposta para viabilizar a implantação desses registros de competências dos indivíduos a fim de formalizar o registro de seus conhecimentos é utilizar dos momentos e práticas de transferência de conhecimento que já se encontram devidamente estabilizadas no núcleo e que ocorrem de maneira mais ampla, ou seja, que abracem coletivamente os indivíduos envolvidos, tais como os fóruns (presenciais e virtuais)/listas de discussão, as comunidades de prática/comunidades de conhecimento e também a prática de educação corporativa, que se encontra com uma média regular. No momento da transferência do conhecimento, ao recolher quais são as áreas de conhecimento específicas compartilhadas e seus autores, começa a viabilidade da construção de um registro sobre quem são os profissionais mais aptos dentro de cada especificidade.

Vale ressaltar que não é apenas a área de formação e atuação dos profissionais que deve ser recolhida em caso de se implementar um banco de competências individuais, pois o conhecimento, sendo algo muito íntimo e pessoal, principalmente no que se refere ao conhecimento tácito, toda a sua totalidade gerada pela experiência particular do profissional deve ser considerada. Almeida et. al. (2016, p. 69) traz a importância dessas competências estarem mapeadas ao passo que é a combinação delas que é responsável pelos processos de uma organização em geral:

É fundamental entendermos que as organizações são resultados de um conjunto de competências que, aliadas e trabalhando em conjunto, promoverão resultados almejados. Podemos dividir essas competências em institucionais e individuais. [...] As individuais, relacionadas aos funcionários, significam o saber agir ao mobilizar, integrar, transferir conhecimentos, recursos e habilidades que adicionem valor econômico à organização e valor social ao indivíduo.

Assim, é necessário pensar em estratégias de viabilização e aplicabilidade de um mapeamento dessas competências dentro dos núcleos da Ativa Incubadora, que, inclusive, sendo uma incubadora sistêmica onde os núcleos se integram entre si, poderá ter grande proveito ao garantir que os núcleos conheçam quais são as competências de profissionais que atuam em atividades da incubadora até mesmo em núcleos geograficamente distantes do seu e que ainda não tiveram a oportunidade de ter contato. 
A respeito de práticas que possibilitam a gestão do conhecimento como registros de informações que podem ser acessadas dentro dos núcleos, tais como memória organizacional/lições aprendidas/banco de conhecimentos, ferramentas de colaboração, como portais, intranets e extranets, gestão de conteúdo e gestão do capital intelectual/gestão dos ativos intangíveis; encontra-se equilíbrio em suas classificações, pois embora apresentem médias regulares, estão perpetuadas como práticas já implantadas ou com plano de implantação na maioria dos núcleos. Isso é importante, pois, no momento em que há a defasagem no âmbito da busca por quais profissionais são mais capacitados em determinados tipos de conhecimentos e, portanto, poderiam ser fontes da transferência deles, os registros suprem de forma parcial essa necessidade para aqueles que se encontram nesse caráter de necessidade.

Não obstante, isso demonstra o potencial dos núcleos em estabelecer práticas de registro de conhecimento que, dessa forma, poderia ser melhor utilizado também para otimizar os registros a respeito dos profissionais que possuem esse conhecimento, provendo um melhor desempenho nos nas práticas associadas a essas determinações que se encontram severamente defasadas.

Por fim, cabe uma observação para a prática de gestão eletrônica de documentos (GED), que também sendo importante para o registro e fluxo de conhecimento, encontra-se com média regular de 1,286, entretanto, apenas porque nas amostras $A$ e B seu estágio foi classificado com a melhor colocação, sendo está a "(4) Já estão implantadas e apresentando resultados importantes e relevantes.", mas obteve classificação (1) em outro núcleo e (0) em todos os quatro demais. Assim, é perceptível um desequilíbrio palpável entre os núcleos, o que pode ser suprido através do compartilhamento dos núcleos $\mathrm{A}$ e $\mathrm{B}$ com o restante através de práticas como a socialização de melhores práticas e narrativas.

\section{CONSIDERAÇÕES FINAIS}

Respondendo ao que norteava este estudo é possível perceber que a Ativa Incubadora de Empresas do IFMT, através de seus núcleos, possui as práticas de GC 
em seu cotidiano de forma abrangente, ao passo que a maioria possui percepções de implantação ou implantadas, entretanto, ressalta-se que mesmo com essas percepções, grande parte das práticas não ocorre, ainda, de forma intensificada e que gere resultados.

Todavia, a existência dessa percepção das práticas entre os núcleos corrobora com a ligação entre GC e inovação, pois, sendo a incubadora um habitat de inovação ao passo que lida com o empreendedorismo inovador, mesmo a Gerência Executiva não possuindo a aplicabilidade da GC como uma prioridade e maioria dos núcleos não tendo familiaridade com o termo, as práticas se perpetuam como estratégias atuais ou futuras na maioria deles.

Entretanto, é nítido o desequilíbrio entre os núcleos ao passo que as médias variam entre "2,611", "2,389", “1,500", “1,000", “0,667”, "0,500" e "0,333", mostrando que apesar de haver aqueles onde as práticas já apresentam resultados relevantes, ainda são maioria os núcleos onde as práticas não se encontram tão fortemente estruturadas. Contudo, são pontos fortes em um aspecto geral as práticas de transferência do conhecimento, o que pode ser utilizado como estratégia institucional através de ações coletivas entre os núcleos para que as práticas exitosas possam ser socializadas e abraçadas também pelos núcleos defasados.

Como sugestão de estudo futuro sugere-se a estruturação de um mapeamento de processos que seja capaz de indicar com precisão como as práticas de GC que atualmente encontram-se empregadas de maneira satisfatória podem ser utilizadas para otimizar os processos envolvidos naquelas que se encontram defasadas, nivelando assim o ciclo de GC dentro dessas instituições através do uso de práticas que já possuem.

\section{REFERÊNCIAS}

ALVARENGA NETO, R. Gestão Do Conhecimento Em Organizações: Proposta De Mapeamento Conceitual Integrativo. Orientador: Ricardo Rodrigues Barbosa. 2005. 400 p. Tese (Doutorado em Ciência da Informação) - Programa de Pós Graduação 
em Ciência da Informação da UFMG, Belo Horizonte, 2005. Disponível em: <http://hdl.handle.net/1843/EARM-6ZGNE6> Acesso em: 23/08/2020.

ALMEIDA, A; BASGAL, D. M; RODRIGUEZ, M. Y; FILHO, W. Inovação e Gestão do Conhecimento. Rio de Janeiro: FGC Editora, 2016.

ANPROTEC. Mecanismo de geração de empreendimentos e ecossistemas de inovação. 2019. Disponível em: <http://anprotec.org.br/site/sobre/incubadoras-eparques/> Acesso em 23/08/2020.

ATIVA. Onde estamos. $2019 . \quad$ Disponível em $<$ https://ativa.ifmt.edu.br/?page_id=433> Acesso em 23/12/2019.

BATISTA, F. O Desafio da Gestão do Conhecimento nas áreas de Administração e Planejamento das Instituições Federais de Ensino Superior (IFES). Brasília: Ipea, $2006 . \quad$ Disponível em: $<$ https://www.ipea.gov.br/portal/index.php?option=com_content\&view=article\&id=477 9> Acesso em 23/08/2020.

BATISTA, F. Modelo de Gestão do Conhecimento para a Administração Pública Brasileira: Como implementar a Gestão do Conhecimento para produzir resultados em benefício do cidadão. Brasília: Ipea, 2012. Disponível em: <http://repositorio.ipea.gov.br/handle/11058/754> Acesso em: 23/08/2020.

BUREN, I. M; RAUPP, F. Compartilhamento do Conhecimento em Incubadoras de Empresas: um Estudo Multicasos das Incubadoras de Santa Catarina Associadas à Anprotec. 2003. Anais do Enanpad. Disponível em $<$ http://www.anpad.org.br/admin/pdf/enanpad2003-act-0915.pdf> Acesso em 23/08/2020

CONG, X; PANDYA, K. V. Issues of Knowledge Management in the Public Sector. The Electronic Journal of Knowledge Management, 1, pp. 25-33. [online] Disponível em: < http://www.ejkm.com/issue/download.html?idArticle=17> Acesso em $23 / 08 / 2020$ 
DEPINÉ, A; TEIXEIRA, C. S. Habitats de inovação: conceito e prática - São Paulo: Perse. 294p. v.1: 2018. Disponível em: < http://via.ufsc.br/wpcontent/uploads/2018/05/HABITATS-DE-INOVACAO-conceito-e-pratica.pdf> Acesso em 23/08/2020.

FIALA, N; ANDREASSI, T. As incubadoras como ambientes de aprendizagem do empreendedorismo. Administração: Ensino e Pesquisa. Rio de Janeiro, V. 14, № 4, p. 759-783, Out Nov Dez, 2013. Disponível em: <https://raep.emnuvens.com.br/raep/article/view/51/164> Acesso em 23/08/2020.

FURLANI, T. Engajamento De Corporações Com Startups Na Quarta Era Da Inovação: Recomendações E Sugestões. Dissertação (mestrado) - Universidade Federal de Santa Catarina, Centro Tecnológico, Programa de Pós-Graduação em Engenharia e Gestão do Conhecimento, Florianópolis, 2018. Disponível em: <https://repositorio.ufsc.br/handle/123456789/194468> Acesso em: 23/08/2020.

GIL, A. C. Como elaborar projetos de pesquisa. São Paulo: Editora Atlas S.A. - $4^{a}$ Edição, 2002.

IFMT. O que é Incubadora de Empresas? 2019. Disponível em < http://proex.ifmt.edu.br/conteudo/pagina/o-que-e-incubadora-de-empresas/> Acesso em: 23/08/2020.

IFMT. Regimento Interno da Ativa Incubadora de Empresas, 2017. Disponível em: $<$ http://proex.ifmt.edu.br/media/filer_public/8d/77/8d776283-0e4a-4c2c-85cd293ee6d57322/resolucao_0842017.pdf> Acesso em: 23/08/2020.

LIMA, N; ZIVIANI, F; REIS, R. V. Estudo das práticas de gestão do conhecimento no Instituto Federal de Educação, Ciência e Tecnologia do Maranhão. Encontros Bibli: revista eletrônica de biblioteconomia e ciência da informação, Florianópolis, v. 19, n. 41, p. 105-126, Dez. 2014. ISSN 1518-2924. Disponível em: <https://periodicos.ufsc.br/index.php/eb/article/view/1518-2924.2014v19n41p105>. Acesso em: 23 ago. 2020. doi:https://doi.org/10.5007/1518-2924.2014v19n41p105. 
MAGNANI, M; HEBERLÊ, A. Introdução a Gestão do Conhecimento: Organizações como sistemas sociais complexos. - Pelotas: Embrapa Clima Temperado, 2010.

Disponível em:

http://www.infoteca.cnptia.embrapa.br/infoteca/handle/doc/867731> Acesso em: 22/08/2020.

MARTINS, G; et. al. A interação universidade/empresa nas Incubadoras de Empresas de Base Tecnológica de Minas Gerais. Anais do XXIV Simpósio de Gestão de Inovação Tecnonlógica. Gramado, Out. 2006. Disponível em: <http://www.anpad.org.br/admin/pdf/RED801.pdf> Acesso em 23/08/2020.

MÜLLER, R; et. al. Contribuições da Gestão do Conhecimento para as Incubadoras de Empresas: uma investigação nas incubadoras tecnológicas da cidade Curitiba, PR. Anais do XVI Congresso Latino-iberoamericado de Gestão de Tecnologia, Out. 2015.

Disponível em:

http://altec2015.nitec.co/altec/papers/295.pdf> Acesso em: 23/08/2020.

PIMENTA, R. C. Q.; NETO, M. Gestão da Informação: um estudo de caso em um instituto de pesquisa tecnológica. Prisma.com, revista de Ciências e Tecnologias de Informação e Comunicação. № 9, p. 128-157, 2009. Disponível em <http://ojs.letras.up.pt/index.php/prismacom/article/view/2055/3100> Acesso em: 23/08/2020.

PROBST, G; RAUB, S; ROMHARDT, K. Gestão do conhecimento: os elementos construtivos do sucesso. Porto Alegre: Bookman, 2002.

RAUPP, F; BEUREN, I. M. Gestão Do Conhecimento Em Incubadoras Brasileiras. Future Studies Research Journal: Trends and Strategies [FSRJ], [S.I.], Vol. 2, №. 2, p. 186-210, Dez. 2010. ISSN 2175-5825. Disponível em: $<$ https://www.revistafuture.org/FSRJ/article/view/61/99>. Acesso em: 23/08/2020.

SETZER, V. W. Dado, Informação, Conhecimento e Competência, 2014. Disponível em: < https://www.ime.usp.br/ vwsetzer/dado-info.html> Acesso em: $23 / 08 / 2020$ 
SILVA, S. A relevância das incubadoras de empresas no mundo contemporâneo. Ponto-e-Vírgula : Revista de Ciências Sociais, [S.I.], n. 6, mar. 2013. ISSN 1982-4807. Disponível em: <https://revistas.pucsp.br/pontoevirgula/article/view/14049/10351> Acesso em: 23/08/2020.

STRAUHS, F; et. al. Gestão do Conhecimento nas Organizações - Curitiba: Aymará Educação, 2012. - (Série UTFinova). ISBN 978-85-7841-783-3 (material impresso) ISBN 978-85-7841-784-0 (material virtual). Disponível em: < http://repositorio.utfpr.edu.br/jspui/bitstream/1/2064/1/gestaoconhecimentoorganizac oes.pdf> Acesso em: 22/08/2020.

WIIG, K., M. Application of Knowledge Management in Public Administration. Paper Prepared For Public Administrators of the City of Taipei, Taiwan, ROC, 2000. Later published as Wiig, K.M. (2002) 'Knowledge management in public administration', Journal of Knowledge Management, Vol. 6, No. 3, pp. 224-239.

WIIG, K., M. The Importance of Personal Knowledge Management in the Knowledge Society. 2011 for "Personal Knowledge Management: Individual, Organisational and Social Perspectives" A book edited by Dr David J Pauleen and Professor G E Gorman. Disponível em: < https://www.researchgate.net/publication/271509540_The_Importance_of_Personal_ Knowledge_Management_in_the_Knowledge_Society> Acesso em: 23/08/2020.

Enviado: Setembro, 2020.

Aprovado: Outubro, 2020. 